\title{
Induced mutagenesis for improving water stress tolerance in durum wheat (Triticumturgidum L. subsp. durum)
}

\author{
Meryem Elyadini ${ }^{1,2, *}$, Abdelkarim Guaadaoui ${ }^{2,3}$, Souad ElHajjaji ${ }^{2}$, Najoua Labjar $^{2,4}$, Mustapha Labhilili $^{5}$, Fatima \\ Gaboune $^{5}$, and Mohammed Azeqour ${ }^{1}$ \\ ${ }^{1}$ Department of Biology, Faculty of Sciences and Technology - Mohammedia, Hassan the Second University, Mohammedia, Morocco. \\ ${ }^{2}$ Center of Water, Natural Resources, Environment and Sustainable Development (CERNE2D), Faculty of Sciences, Mohammed V \\ University in Rabat, Morocco. \\ ${ }^{3}$ Department of Biology, Faculty of Sciences - Oujda (FSO), Mohammed the First University (UMP) - Oujda, Morocco. \\ ${ }^{4}$ Higher Normal School of Technical Education (HNSTE). Mohammed V University in Rabat, Morocco. \\ ${ }^{5}$ National Institute of Agronomic Research (INRA) BP: 10101, Rabat, Morocco.
}

\begin{abstract}
Over the Water deficit is considered to be one of the most important limiting factors for crop productivity worldwide. Thus, it is important to use water resources more efficiently. One of the ways to conserve water and respond to the climate change is by using appropriate crop species and cultivars, notably which have low requirements for water.Chemical mutagens have contributed immensely to the development of a wide range of genetic variability and the improvement of several crop plants, including durum wheat. This study has the aim of understanding the effect of water stress on some morpho-physiological parameters and identifying tolerant lines to water stress from an EMS-mutated population in durum wheat. The results, under moderate (T1) and severe (T2) conditions of water stress, show the positive effect of mutagenesis on the population resulting in tolerantmutated linesto water deficit. Compared to the non-mutated, $32.15 \%$ of lines have a higher specific leaf weight; $57.14 \%$ of lines have a better ability to maintain a high water content and $75 \%$ of all lines demonstrate a very high intensity of chlorophyll fluorescence .In sum, this study has revealed the improvement of water stress tolerance in some induced durum wheat mutants.
\end{abstract}

\section{Introduction}

Durum wheat (Triticumturgidum L. ssp. durum) is a vital cereal crop that provides substantial economic output in the Mediterranean region[1]. Durum is better adapted than common hexaploid wheat to semi-arid environments. Butits production and quality suffer greatly from several abiotic stress constraints including water deficiency and heat[2], [3]. Water is very essential for smooth running of various metabolic activities inside plants. Water deficit is considered to be one of the most important limiting factors for crop productivity worldwide and especially in the Mediterranean area[4].

The proposed scenarios for climate change indicate that water availability will be a limiting factor for many countries in the following years[5]. So, the water deficit is a big challenge for plant breeders around the world who need to develop cultivars which could sustain such stress conditions without significant yield loss[6], [7].In drought conditions, plants usually respond in the form of stunted growth due to its adverse effects on different molecular, biochemical, physiological and morphological processes of the plant. Such changes are totally related to the growth stage, time and severity of environmental stresses[8], [9].
For screening and selection of tolerant genotypes to uphold productivity under water stress conditions, the understanding of physiological mechanisms is very essential[10]. It is reported that drought related physiological parameters were dramatically reduced under water stress conditions as compared to normal conditions[11]. For instance,plant exposure to moisture stress lowers down the relative water content (RWC), leaf water potential and osmotic potential[12]. The foliar photosynthetic rate of higher plants is known to decrease as the RWC and the leaf water potential decrease[13]. The decrease in photosynthesis of leaves is usually caused by stomatal limitation under mild to moderate drought conditions and non-stomatal limitation under severe drought conditions[14]. Moreover, under mild to moderate drought stress, LA decreases and an early leaves senescence occurs[15].

In an early future, drought is expected to increase due to climate change in most parts of the world[16], [17]. Hence, it is an urgent need, for this moment, to breed cultivars with enhanced drought tolerance and high water use efficiency, which can be achieved by employing both conventional plant breeding and genetic engineering[18]. Because of their use for the development of new mutant varieties, induced mutations

\footnotetext{
*Corresponding author: meryem-elyadini@um5.ac.ma melyadini@gmail.com
} 
have played an important role in meeting the challenges linked to global food and nutritional security.

Chemical mutagens, especially the Ethyl Methyl Sulfonates (EMS), are used to induce mutations in plants. Through chemical reactions within the genome, EMS affects the DNA molecule. Thus, the mutagenic treatments could induce a wide range of genetic variability for use in crop improvement programs and new varieties development[18]-[20]. Mutant lines should indicate water stress tolerance by showing a relationship between phenotype and genotype in a selection process [21], [22].

The present work objectives are i) the identification of the water stress effect on various morphological and physiological characters in mutant lines derived from the CHAM1 variety of durum wheat by the EMS mutagen under normal and deficit irrigation; and ii) the selection of new mutant durum wheat genotypes presenting a better ability to grow and a satisfactory yield under water stress conditions. This information will aid to identify the best cultivars that could be used as genitors in future breeding programs.

\section{Material and Methods}

\subsection{Study Material}

This study is carried out on a mutated population of durum wheat (Triticum durum Desf.) from the CHAM1 variety.Seedswerepreviously treated with $0.6 \%$ of the mutagenic chemical agent EMS (Ethyle Methane Sulfonates). 3215 seeds of the M1 generation were sown in a greenhouse at the National Institute of Agronomic Research (INRA) - Rabat, Morocco to obtain M2, M3 and M4generations.

Out of 2505 M5lines sown in the experimental station,Marchouch-Morocco, an annual selection was made according to the height of the plant, the vigor, the yield and the resistance to diseases until obtaining individuals of the M8 generation. Then, out of 262 selected M9 lines, 40 lines were isolated to make the study material for this work. These lines are characterized by a high grain yield compared to the nonmutated parent CHAM1.

\subsection{Methods}

\subsubsection{Tests organization}

Two controlled experiments were carried out. The first was carried out under the condition of good water supply (T0), in order to characterize the mutation effect on the variations of the morpho-physiological parameters. These by comparison of the mutated lines -selected by their high grain yield- and the non-mutated CHAM1 durum wheat (control). The second experiment was carried out under two water stress conditions-moderate (T1) and severe (T2) in order to characterize the behavior of the mutated lines under the applied stresses and the studied parameters, in comparison to the control.

\subsubsection{Preparation of pots and seedlings}

The grains of the 40 selected mutant lines were sown under controlled conditions in a greenhouse equipped with a computerized electronic system at the INRARabat. The microclimatic conditions are $22^{\circ} \mathrm{C}$ of temperature, $50 \%$ relative humidity of the air and photoperiodism programmed at $08 \mathrm{~h}$ of darkness $/ 20 \mathrm{~h}$ of light. The sowing was carried out manually at the rate of 7 grains per plastic pots of $5 \mathrm{Kg}$ of a mixture substrate composed by $2 / 3$ soil and $1 / 3$ peat.

\subsubsection{Determination and application ofstress levels}

The pots were simultaneously irrigated twice a week until the end of the production stage. After, the pots were divided into two lots constituting respectively control (T0) and stressed plants. The water stress is applied by a watering stop. The water stress duration (l) is one week for moderate water stress (T1) and two weeks for severe water stress (T2).For all morphological and physiological parameters, the measurements were made on the flag leaf.

\section{a. Morphological parameters}

i. Leaf area $\left(\mathrm{LA}, \mathrm{cm}^{2}\right)$

The LA is a necessary index for determining growth. The measurement is carried out using a planimeter (AM300 Portable Leaf Area Meter) according to the method reported initially by[23].

\section{ii. Specific leaf weight (SLW, $\mathrm{mg} / \mathrm{cm}^{2}$ )}

Cut leaves are weighed immediately to obtain fresh weight (FW). The leaf specific weight (SLW) is determined by the formula[24], [25]:

\section{$\operatorname{SLW}\left(\mathbf{m g} / \mathrm{cm}^{2}\right)=$ FW/SLA}

\section{b. Physiological parameters}

i. Relative water content (RWC, \%)

Relative water content (RWC) is one of the criteria for assessing drought tolerance. It decreases when water stress increases. According to the method of(Clarke and McCaig, 1982) the cut flag leaves are directly weighed (fresh weight,FW) and immersed in test tubes filled with distilled water.Then, the tubes are placed in a cool dark place. After 24 hours, the saturated leaves are reweighed (turgor pressure weight, TW). Finally, the sample is put to dry in an oven at $80^{\circ} \mathrm{C}$ and weighed one last time after 48hours (dry weight,DW). The relative water content is determined according to the formula:

\section{RWC $(\%)=($ FW - DW $) /($ TW - DW $) \times 100$}

ii. Quantum yield of PSII (ФPSII)

Chlorophyll fluorescence is a precise intrinsic indicator of the first stages of photosynthesis, photosystems II (PSII)in this case. Its intensity is inversely linked to photosynthetic yield and therefore to the vitality of plants[27].

The chlorophyll fluorescence measurements were carried out on the intact leaves - stillattached, using a portable fluorometer (chlorophyll fluorometer, Model 0os-30, USA). The measured fluorescenceFo (minimum fluorescence) and Fm (maximum fluorescence) assess 
the photochemical efficacy of PSII. Thus, after adaptation to darkness for 3 minutes, the maximum photosynthetic yield of the PSII is calculated according to the formula:

$$
\text { Qmax PSII }=(\text { Fm-Fo }) / \text { Fm }
$$

c. Statistical analyzes

The descriptive statistical parameters and variance analyzes were processed using the SAS program (Statistical Analysis System, version 9.1). The graphics were produced by Ms Excel software and using Genstat. The statistical analyzes concerned only 28 lines. The other 12 lines were excluded from the analysis since they did not resist to the applied stresses.

\section{Results and Discussion}

Water stress is considered the most severe of the environmental stresses that affect plant growth and yield. To cope, plants develop adaptation strategies by adjusting leaf growth [28], [29], stomatal conductance [30],photosynthesis [31], [32] and the leaf surface [33],[34]. Here, we report the experimental results with the discussion of the variation of the morphophysiological parameters of the mutated lines, either under the condition of good water supply and water stress conditions, in addition to the correlation between the both variations.

\subsection{Variation of the morpho-physiological parameters of the mutated lines under the condition of good water supply}

The effect of the mutation on the variations in morphophysiological parameters between the mutated lines and the control (CHAM1 not mutated) is presented in the form of histograms (Fig..1).The descriptive analysis shows that the variation distribution follows the normal law, with a median regrouping a maximum number of lines.

Indeed, under the conditions of good water supply, the mutant lines LA fluctuates between $8.37 \mathrm{~cm}^{2}$ and $27.61 \mathrm{~cm}^{2}$ while the control records an average of 22.6 $\mathrm{cm}^{2}$ (Fig. 1a). Thus, $27.77 \%$ of the lines show a very small assimilating surface than that of the non-mutated control. However, $30.55 \%$ have larger assimilating surfaces. The rest recorded a value close to the control average. In $16.21 \%$ of the lines, the recorded values of the SLW are between $20.10 \mathrm{mg} / \mathrm{cm}^{2}$ and $31.52 \mathrm{mg} / \mathrm{cm}^{2}$. They are much higher than that of the control which is $13.64 \mathrm{mg} / \mathrm{cm}^{2}$ (Fig. 1b).

For the RWC (Fig. 1c), and compared to the control which records an RWC of $82.74 \%$, the highest contents are noted in $36.11 \%$ of the lines, with a maximum value of $99.93 \%$. ; whereas, the other lines record more or less low water contents with a minimum value of $62.39 \%$.For the Qmax PSII parameter, the values range from 0.66 to 0.78 ; with $47.22 \%$ of the lines have a higher $\Phi$ PSII, $13.88 \%$ of the lines have a lower SI PSII, while the rest of the lines have values very close to that of the control (Fig. 1d).

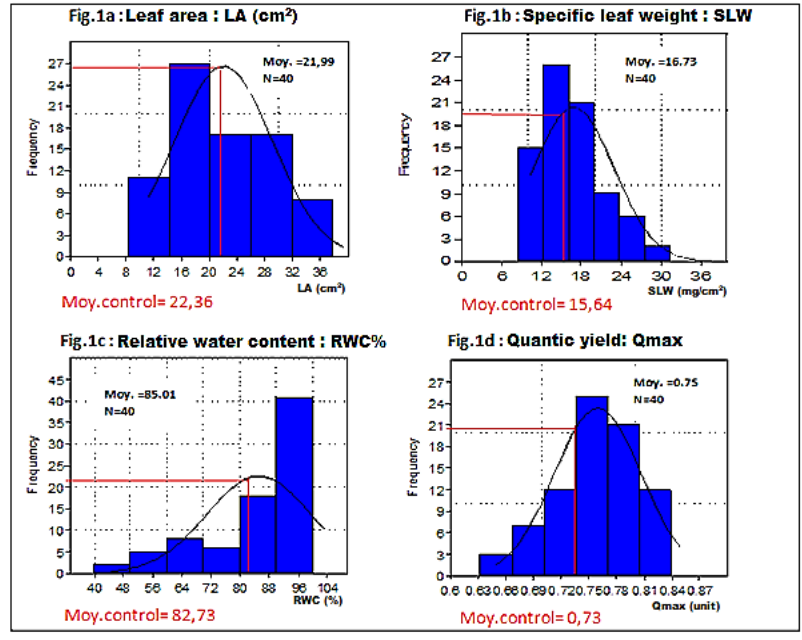

Fig. 1: Distribution of the morpho-physiological characteristics of the mutated lines in comparison with the non-mutated control (CHAM1) under the condition of good irrigation (T0). (In red, the average corresponds to the non-mutated CHAM1 control).

The results of the variance analysis (Table 1) reveal the existence of a high significant variability between the studied lines for all the measured parameters. This is true for all the measured parameters except the SLW. This variability in phenotypic expression of the mutated lines can be explained by the action of the applied mutagen (EMS) on the genomic material. So the mutation carried out was very successful.

The several studies show that chemical mutagen ethyl methane sulphonate (EMS), have been successfully used on wheat[35]. In fact it's more efficient in inducing higher mutation frequency of crop traits compared with physical mutagens, such as gamma radiation[36], [37]. The noted morpho-physiological variability in the studied lines were used to analyze the water stress effect on the behavior of these lines with regard to the various measured parameters.

Table 1: The variance analysis of the different morphophysiological parameters under the condition of good water supply.

\begin{tabular}{|c|c|c|c|c|}
\hline $\begin{array}{c}\text { Variation } \\
\text { factor }\end{array}$ & LA & SLW & RWC & Qmax \\
\hline $\begin{array}{c}\text { Genotype } \\
\text { effect (F1) }\end{array}$ & $0.0090 * *$ & $\begin{array}{c}0.4941 \\
\mathrm{Ns}\end{array}$ & $0.0110^{*}$ & $0.0001 * * *$ \\
\hline
\end{tabular}

LA: leaf area, SLW: specific leaf weight, RWC: relative water content, Qmax: quantum yield PSII

***. Very highly significant effect at the threshold $\alpha<0.1 \%$;

**. Highly significant effect at the threshold $\mathrm{P}<1 \%$;

*. Significant effect at threshold $\mathrm{P}<0.05$;

Ns: Non-specific effect

\subsection{Variation in the morpho-physiological parameters of the mutated lines under water stress conditions}

The results of the variance analysis of the various morpho-physiological parameters, under the condition of water stress (Table 2), reveal the existence of a significant effect of the genotype and the water stress 
treatment for the studied parameters. Significant interactions between the genotype and the treatment were noted positively in the case of quantum yield (Qmax).

Table 2: The variance Analysis of the various morphophysiological parameters under water stress conditions.

\begin{tabular}{|c|c|c|c|}
\hline Variables & $\begin{array}{c}\text { Genotype } \\
\text { effect }\end{array}$ & $\begin{array}{c}\text { Treatment } \\
\text { effect }\end{array}$ & $\begin{array}{c}\text { Interaction } \\
\text { genotype x treatment }\end{array}$ \\
\hline LA & $0.0001 * * *$ & $0.0001 * * *$ & $0.1675 \mathrm{Ns}$ \\
\hline SLW & $0.0528^{*}$ & $0.0214 *$ & $0.4489 \mathrm{Ns}$ \\
\hline RWC & $0.0125^{*}$ & $0.0001 * * *$ & $0.2030 \mathrm{Ns}$ \\
\hline Qmax & $0.0001 * * *$ & $0.0001 * * *$ & $0.0001 * * *$ \\
\hline
\end{tabular}

***. Very highly significant effect at the threshold $\alpha<0.1 \%$;

**. Highly significant effect at the threshold $\mathrm{P}<1 \%$;

*. Significant effect at threshold $\mathrm{P}<0.05$;

Ns: Non-specific effect.

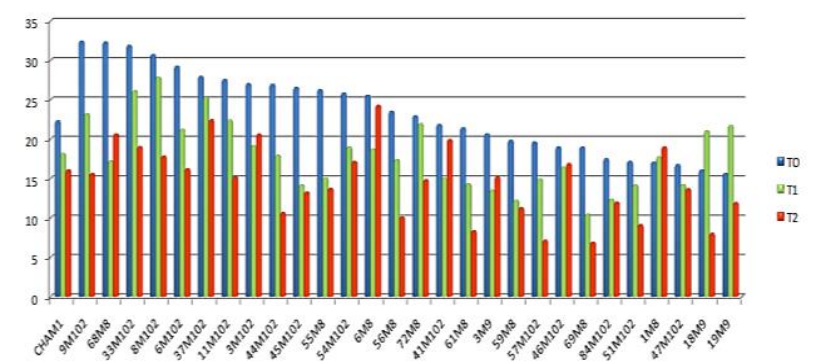

Fig. 2: Variation in the leaf area of the control and 28 mutated lines subjected to different water stress levels

Under moderate stress conditions (T1), there is a decrease in LA in all of the studied lines except for the two lines 19M9 and 18M9which record an increase in this parameter. A clear decrease in the LA is noted in the $45 \mathrm{M} 102$ line with $26.595 \pm 6.26 \mathrm{~cm} 2$ in $\mathrm{T} 0$ conditions and $14.23 \pm 3,38 \mathrm{~cm} 2$ in $\mathrm{T} 1$ condition. However, the 46M102line records LA values very close and vary from $19.045 \pm 4.29 \mathrm{~cm} 2$ (T0)to $16.48 \pm 0.02 \mathrm{~cm} 2$ (T1). In this regard, there is a regression percentage of $46.49 \%$ in the $45 \mathrm{M} 102$ line against $13.46 \%$ in the $46 \mathrm{M} 102$ line. The non-mutated CHAM1 control records LA values between $22.364 \pm 2.67 \mathrm{~cm} 2(\mathrm{~T} 0)$ and $18.223 \pm 1.41$ $\mathrm{cm} 2$ (T1), with a regression of $18.52 \%$.

Under severe stress conditions (T2), all of the mutated lines maintain their decrease in the LA, except in 68M8, 3M102, 6M8, 41M102, 1M8, 3M9 and 46M102genotypes where an increase in LA is noted. The percentages of this increase range from $7.62 \%$ in the $3 \mathrm{M} 102$ line to $32.17 \%$ in the $41 \mathrm{M} 102$ line.It is noted that in all the water stress conditions, the 47M102 line have a slight decrease in LA compared to the non-mutated control CHAM1, while the 1M8 line maintains an increase in LA.

Leaf area (LA) plays an important role in plant growth analysis. LA and leaf weight measurements are required to calculate several growth indices, like specific leaf weight (SLW). Under conditions of water stress, vegetative development is strongly disturbed by a significant decrease in size and LA. This result is in perfect agreement with what[38]found. In our experimentation and under the condition of water stress, we note $67.85 \%$ of the mutated lines which present the same evolution as that of the control with a regression of the LA. This reduction is considered to be one of the plants' avoidance strategies for water stress. In fact, the water stress significantly reduced LA due to the reduced cell division. Water stress may reduce turgor pressure and hence cell expansion, resulting in approximately the same dry mass being contained within a smaller LA, thus raising density[39]. The plant closes its stomata to conserve the water resources, which allows them to survive[40], but its productivity decreases because less carbon could be assimilated.

For the $32.15 \%$ of lines $-19 \mathrm{M} 9 ; 18 \mathrm{M} 9 ; 68 \mathrm{M} 8$; 3M102; 6M8; 41M102; 1M8; 3M9; 46M102 and $47 \mathrm{M} 102-$ there is an increase in LA under water stress. These lines seem to support a water restriction better without appreciably modifying their leaf surface. The resistance of this portion of the mutated lines to the water deficit could be explained by an osmotic adjustment of the cells. This tolerance process has been reported by[41].Thus, the increase in tolerance to dehydration is achieved by the anatomical properties of the water-conducting elements allowing higher tension on the column and keeping the stomata open. So the productivity does not decrease.

\subsubsection{Effect of stress on the specific leaf weight}

Compared to the non-mutated control (CHAM1), the effect of water stress on the SLW, under different stress levels, is manifested in different behavior (Fig. 3).

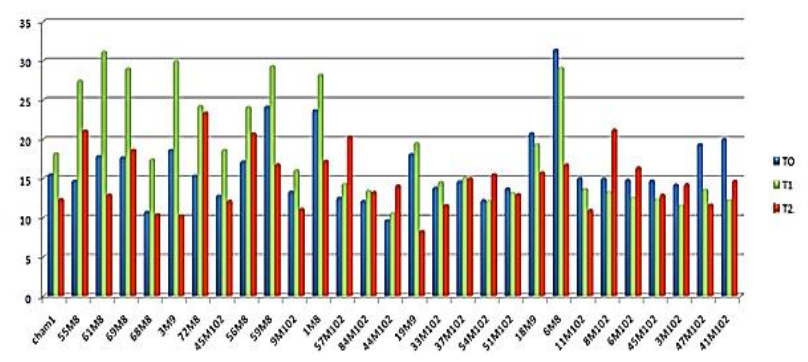

Fig. 3: Variation in the SLW of the control and 28 mutated lines subjected to different water stress levels.

The increase in SLW values in the 55M8 line vary from $14.82 \pm 1.5 \mathrm{mg} / \mathrm{cm} 2$ (T0) to $27.58 \pm 0.91$ $\mathrm{mg} / \mathrm{cm} 2(\mathrm{~T} 1)$, with an increase percentage of $86.09 \%$.Nevertheless, the 37M102 line records SLW values very close, with variations from $14.72 \pm 1.39$ $\mathrm{mg} / \mathrm{cm} 2$ (T0) to $15.15 \pm 0.27 \mathrm{mg} / \mathrm{cm} 2$ (T1), so an increase percentage of $2.95 \%$. Regarding the control, the SLW values are $15.64 \pm 2.14 \mathrm{mg} / \mathrm{cm} 2$ (T0) and $18.27 \pm 1.87$ $\mathrm{mg} / \mathrm{cm} 2$ (T1), so an increase percentage of $16.82 \%$.

Under T2 conditions, and compared to the control, drops in SLW values were noted in the studied lines. However, 8 genotypes -57M102, 8M102, 44M102, 6M102, 54M102, 3M102, 41M102 and 45M102- show an increase in SLW with variations between $4.79 \%$ in the $45 \mathrm{M} 102$ line and $41.85 \%$ in the $57 \mathrm{M} 102$ line. The $44 \mathrm{M} 102$ and 57M102 lines maintain their increase in SLW under all water stress conditions. 
The present study shows a significant correlation between the SLW and the LA. This finding is reported by[42] pointing out that the leaf specific weight of durum wheat increases under water stress. This increase, in some varieties under stress, is highly correlated with the reduction in LA[39].

\subsubsection{Effect of stress on the relative water content.}

The analysis of the relative water content allows describing in a global way the hydric status in response to water stress, and to evaluate the ability to achieve good osmoregulation and to maintain cellular turgor pressure[43].

Compared to the control, the evolution of the relative water content, under the water stress effect, shows a very highly significant decrease in the relative water content in all the studied lines $(\mathrm{p}<0.001)$ as and as the water deficit increases (Fig. 4).

The decrease in RWC is noted in $35.71 \%$ lines, namely 33M102, 45M102, 47M102, 9M102, 56M8, 68M8, 54M102, 57M102, 72M8 and 41M102. They are the most drought tolerant of their non-mutated CHAM1 parent. The recorded decreases in these lines varied from $0.07 \%$ in the $45 \mathrm{M} 102$ line to $5.97 \%$ in the $72 \mathrm{M} 8$ line, compared to the control, which has a regression percentage of $7.37 \%$. On the other hand, there is a slight increase in the water content in $10.71 \%$ of lines $51 \mathrm{M} 102$, 55M8 and 37M102- despite the conditions of water stress.

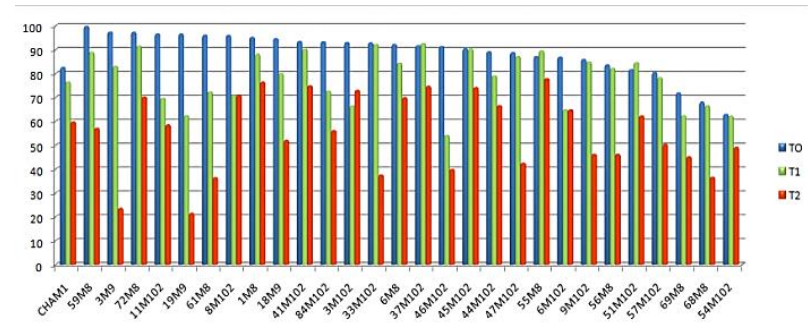

Fig. 4: Variation in relative water content of the control and 28 mutated lines subjected to different water stresslevels.

The decrease in RWC is noted in $35.71 \%$ lines, namely 33M102, 45M102, 47M102, 9M102, 56M8, 68M8, 54M102, 57M102, 72M8 and 41M102. They are the most drought tolerant of their non-mutated CHAM1 parent. The recorded decreases in these lines varied from $0.07 \%$ in the $45 \mathrm{M} 102$ line to $5.97 \%$ in the $72 \mathrm{M} 8$ line, compared to the control, which has a regression percentage of $7.37 \%$. On the other hand, there is a slight increase in the water content in $10.71 \%$ of lines $51 \mathrm{M} 102,55 \mathrm{M} 8$ and 37M102- despite the conditions of water stress.

These results are similar to those of[43], [44], confirming that the water content of durum wheat leaves decreases proportionally with the reduction of water contained in the soil. This decrease is faster in susceptible varieties than in resistant varieties. It is reported that high relative water content is a resistant mechanism to drought, and that high relative water content is the result of more osmotic regulation or less elasticity of tissue cell wall[45].

In severe stress (T2), a clear decrease in water content is observed in all genotypes, except for the $3 \mathrm{M} 102$ line, while the $6 \mathrm{M} 102$ and $8 \mathrm{M} 102$ lines have identical values to those of the $\mathrm{T} 1$ conditions. According to[46], the maintenance of a relatively high value of the relative water content, under stress conditions, can result from two adaptation mechanisms: maintenance of a high elasticity of the tissues or reduction of osmotic pressure. Incidentally, the lines which remain stable or which show a slight increase in this parameter, despite the stress conditions, are more water stress tolerant compared to the control.

\subsubsection{Effect of stress on the quantum yield of the PSII (ФPSII).}

Differences in behavior are recorded in the different lines studied at different levels of stress (Fig. 5).

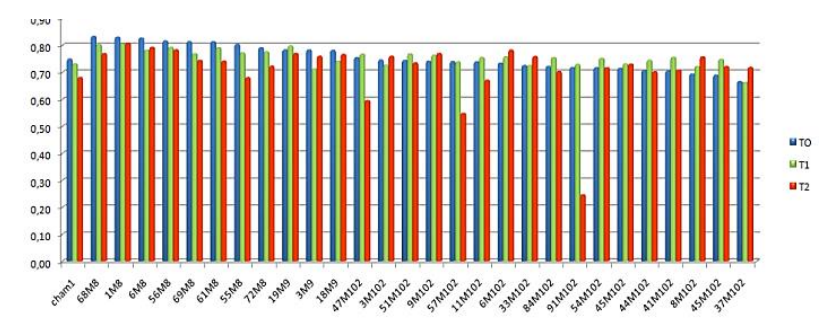

Fig. 5: Variation in the PSII quantum yield of the control and 28 mutated lines subjected to the different water stress levels.

The differences noted between the mutated lines for the fluorescence parameters in this study, especially the quantum yield, indicate that this technique is useful as a tool for screening for tolerance to heat stress in durum wheat. Indeed, several studies have been conducted to assess tolerance to thermal stress using this technique[34].

For $\mathrm{T} 1$ conditions, all the studied lines have a quantum yield of PSII (ФPSII) comparable to the irrigated control. However, in comparison with the CHAM 1 control, $14.28 \%$ of studied lines $-33 \mathrm{M} 102$, 57M102, 37M102 and 72M8- show a slight decrease in ФPSII, with a regression percentage of $0.11 \%, 0,13 \%$, $0.52 \%$ and $1.96 \%$ respectively, while that of the control is $2.37 \%$.

The $\Phi$ PSII values in T2 conditions vary from $0.81 \pm$ 0.011 in the $1 \mathrm{M} 8$ line to $0.25 \pm 0.083$ in the $91 \mathrm{M} 102$ line which exhibits a marked reduction. A slight decrease in ФPSII is noted in $35.71 \%$ of mutated lines (44M102, 84M102, 51M102, 19M9, 56M8, 1M8, 68M8, 18M9, $6 \mathrm{M} 8$ and $3 \mathrm{M} 9$ ). They show a less significant decrease than the CHAM 1control. However, $25 \%$ of lines (6M102, 9M102, 45M102, 33M102, 41M102, 46M102 and $8 \mathrm{M} 102$ ) record an increase in ФPSII in the two levels of water stress.

The different performance of effective quantum yield of PSII (ФPSII), indicated that the electron transport processes were influenced distinctly by water stress in the given $75 \%$ of lines. Drought has significant effect on ФPSII in these lines: the values of this parameter 
gradually decreased during the treatment indicating that electron transport processes were partly down-regulated in these genotypes.

For 6M102, 9M102, 45M102, 33M102, 41M102, $46 \mathrm{M} 102$ and $8 \mathrm{M} 102$ lines, results could suggest that these lines have an ability to maintain a high growth in the intensity of chlorophyll fluorescence. This capacity would be the result of the absence of the photochemical activity inhibition of chloroplasts under the conditions of water stress described by [47].

\subsection{Correlation coefficient}

The results show a very highly significant correlation between all the measured parameters, except for the Qmax PSII. This study shows a significant correlation between the SLW and the LA. This finding is reported by[25], [48] who found that the durum wheat SLW increases under saline stress. The increase in SLW in certain varieties under stress is highly correlated with the reduction in LA.

Table 3: Correlation coefficient between the different physiological and morphological traits.

\begin{tabular}{|c|c|c|c|c|}
\hline & LA & SLW & RWC & Qmax \\
\hline LA & 0.0 & $0.0001 * * *$ & $0.0001 * * *$ & $\begin{array}{c}0.1556 \\
\text { NS }\end{array}$ \\
\hline SLW & $0.0001 * * *$ & 0.0 & $0.0051 * *$ & $\begin{array}{c}0.5883 \\
\text { NS }\end{array}$ \\
\hline RWC & $0.0001 * * *$ & $0.0051 * *$ & 0.0 & 0.6504 \\
\hline Qmax & $0.1556 \mathrm{NS}$ & $0.5883 \mathrm{NS}$ & $0.6504 \mathrm{NS}$ & 0.0 \\
\hline
\end{tabular}

\section{Conclusions}

Mutagenesis by EMS has made it possible to create variability in the mutated population, but also to screen new genotypes that are tolerant to conditions of water lack. This tolerance is explained in $32.15 \%$ of mutated lines by their capacity to maintain a leaf water potential, which leads to a limitation of water losses. While in $57.14 \%$ of the mutated lines, tolerance to water deficit resulted in a better ability to maintain a high water content in the plant.

The significant genotype $\mathrm{x}$ treatment interaction indicates that the Qmax PSII parameter could be considered as a valid criterion for the selection of drought tolerant genotypes. Thus, our results reveal that $75 \%$ of the studied lines have a better capacity to maintain the growth of the intensity of chlorophyll fluorescence, and therefore to preserve the structures and the functioning of the QPSII photosynthetic device more than the control.

In the basis of these results, we confirm that the mutagenesis technique made it possible to select new efficientgenotypes. The selected mutant lines of durum wheat could be used for crosses in breeding programs for wheat genetic improvement. More importantly, the obtained results do not need to be confirmed by several years of testing, because it is a mutagenized population of the eighth generation (M8), whose genome presents genetic stability. In perspective, mutations screening from the set of tolerant and interesting genotypes has performed by TILLING technique. Indeed, the selectioned mutants constitute an important reservoir of genes, potentially usable in the improvement of wheat. The obtained results will be published soon.

\section{References}

1. [1] R. Ciccoritti et al., "Hydrothermal grain preprocessing and ultra-fine milling for the production of durum wheat flour fractions with high nutritional value," Food Sci. Technol. Int., vol. 24, no. 3, 2018, doi: 10.1177/1082013217745199.

2. [2] Y. F. Li, Y. Wu, N. Hernandez-Espinosa, and R. J. Peña, "Heat and drought stress on durum wheat: Responses of genotypes, yield, and quality parameters," J. Cereal Sci., vol. 57, no. 3, 2013, doi: 10.1016/j.jcs.2013.01.005.

3. [3] H. Liu, D. R. Bruce, M. Sissons, A. J. Able, and J. A. Able, "Genotype-dependent changes in the phenolic content of durum under water-deficit stress," Cereal Chem., vol. 95, no. 1, 2018, doi: 10.1002/cche.10007.

4. [4] P. Nazeri, A. H. S. Rad, S. A. ValadAbadi, M. Mirakhori, and E. H. Masoule, "Effect of sowing dates and late season water deficit stress on quantitative and qualitative traits of canola cultivars," Outlook Agric., vol. 47, no. 4, 2018, doi: 10.1177/0030727018793658.

5. [5] M. A. J. Parry, P. J. Madgwick, J. F. C. Carvalho, and P. J. Andralojc, "Prospects for increasing photosynthesis by overcoming the limitations of Rubisco," in Journal of Agricultural Science, 2007, vol. 145, no. 1, doi: $10.1017 / \mathrm{S} 0021859606006666$.

6. [6] M. D. Edgerton, "Increasing crop productivity to meet global needs for feed, food, and fuel," Plant Physiology, vol. 149, no. 1. 2009, doi: 10.1104/pp.108.130195.

7. [7] E. Nemeskéri, A. Neményi, A. Bocs, Z. Pék, and L. Helyes, "Physiological factors and their relationship with the productivity of processing tomato under different water supplies," Water (Switzerland), vol. 11, no. 3, 2019, doi: 10.3390/w11030586.

8. [8] W. F. Abobatta, "Plant Responses and Tolerance to Combined Salt and Drought Stress," 2020.

9. [9] A. Guaâdaoui, F. Bouhtit, M. Cherfi, and A. Hamal, "The Preventive Approach of Biocompounactives ( 3 ): A Review in Recent Advances in Cerealsand some Animal-based foods," Int. J. Nutr. Food Sci., vol. 4, no. 2, pp. 189-207, 2015, doi: 10.11648/j.ijnfs.20150402.21.

10. [10] M. Zaharieva, E. Gaulin, M. Havaux, E. 
Acevedo, and P. Monneveux, "Drought and heat responses in the wild wheat relative Aegilops geniculata roth: Potential interest for wheat improvement," Crop Sci., vol. 41, no. 4, 2001, doi: 10.2135/cropsci2001.4141321x.

11. [11] M. M. Maqbool, A. Ali, T. ul Haq, M. N. Majeed, and D. J. Lee, "Response of Spring Wheat (Triticum aestivum L.) to Induced Water Stress at Critical Growth Stages," Sarhad J. Agric., vol. 31, no. 1, 2015.

12. [12] A. Grover, A. Kapoor, D. Kumar, H. E. Shashidhar, and S. Hittalmani, "Genetic Improvement for Abiotic Stress Responses," in Plant Breeding, 2004.

13. [13] D. W. Lawlor and G. Cornic, "Photosynthetic carbon assimilation and associated metabolism in relation to water deficits in higher plants," Plant, Cell Environ., vol. 25, no. 2, 2002, doi: 10.1046/j.0016-8025.2001.00814.x.

14. [14] Z. Wang et al., "Effects of drought stress on photosynthesis and photosynthetic electron transport chain in young apple tree leaves," Biol. Open, vol. 7, no. 11,2018 , doi: 10.1242/bio.035279.

15. [15] A. Yokota, S. Kawasaki, M. Iwano, C. Nakamura, C. Miyake, and K. Akashi, "Citrulline and DRIP-1 protein (ArgE homologue) in drought tolerance of wild watermelon," Ann. Bot., vol. 89, no. SPEC. ISS., 2002, doi: 10.1093/aob/mcf074.

16. [16] F. Khalil, S. Rauf, P. Monneveux, S. Anwar, and Z. Iqbal, "Genetic analysis of proline concentration under osmotic stress in sunflower (Helianthus annuus L.)," Breed. Sci., vol. 66, no. 4, 2016, doi: 10.1270/jsbbs.15068.

17. [17] M. Tayyab et al., "Bioethanol production from lignocellulosic biomass by environmentfriendly pretreatment methods: A review," Applied Ecology and Environmental Research, vol. 16, no. 1. 2018, doi: 10.15666/aeer/1601_225249.

18. [18] F. Khalil, X. Naiyan, M. Tayyab, and C. Pinghua, "Screening of ems-induced droughttolerant sugarcane mutants employing physiological, molecular and enzymatic approaches," Agronomy, vol. 8, no. 10, pp. 1-13, 2018, doi: 10.3390/agronomy8100226.

19. [19] P. Suprasanna, S. J. Mirajkar, V. Y. Patade, and S. M. Jain, "17. Induced mutagenesis for improving plant abiotic stress tolerance," in Mutagenesis: exploring genetic diversity of crops, 2014.

20. [20] E. Meryem et al., "Characterization of New Allelic Variation for Glutenin in EMS-Mutant Durum Wheat Population (Triticum turgidum L. subsp. durum (Desf.))," J. Life Sci., vol. 8, pp. 880888, 2014, doi: 10.17265/1934-7391/2014.11.004.

21. [21] J. Jankowicz-Cieslak and B. J. Till, "Chemical Mutagenesis of Seed and Vegetatively Propagated Plants Using EMS," Curr. Protoc. Plant Biol., vol. 1, no. 4, 2016, doi: 10.1002/cppb.20040.

22. [22] A. Amsal and Ishak-ishak, "Drought
Tolerance and Evaluation of Genetic Changes in Rice Mutant Lines," Am. J. Appl. Sci., vol. 15, no. 1, 2018, doi: 10.3844/ajassp.2018.1.9.

23. [23] M. H. Paul, C. Planchton, and R. Ecochard, "Etude des relations entre le développement foliaire, le cycle de développement et la productivité chez le soja," Ann. Amélio. Plant., vol. 29, pp. 479-492, 1979.

24. [24] J. L. Araus, T. Amaro, J. Casadesús, A. Asbati, and M. M. Nachit, "Relationships between ash content, carbon isotope discrimination and yield in durum wheat," Aust. J. Plant Physiol., vol. 25, no. 7, 1998, doi: 10.1071/PP98071.

25. [25] Zeghida A., R. Amrani, F. Djennadi, R. Ameroun, A. A. Khldoun, and M. Belloucif, "Etude de la variabilité de réponse des plantules de blé dur (Triticum durum Desf) à la salinité. Céréaliculture," ITGC, no. 42, p. 5p, 2004.

26. [26] J. M. Clarke and T. N. McCaig, "ExcisedLeaf Water Retention Capability as an Indicator of Drought Resistance of Triticum Genotypes," Can. J. Plant Sci., vol. 62, no. 3, pp. 571-587, 1982, doi: 10.4141/cjps82-086.

27. [27] M. Samira, H. Hichem, F. Boughalleb, and D. Mounir, "Effet de l'interaction lumiere-salinite sur l'activite du photosysteme ii des feuilles excisees de maïs," African Crop Sci. J., vol. 23, no. 4, 2015, doi: 10.4314/acsj.v23i4.4.

28. [28] F. Morales et al., "Photosynthetic metabolism under stressful growth conditions as a bases for crop breeding and yield improvement," Plants, vol. 9, no. 1. 2020, doi: 10.3390 /plants9010088.

29. [29] A. Tribulato, S. Toscano, V. Di Lorenzo, and D. Romano, "Effects of water stress on gas exchange, water relations and leaf structure in two ornamental shrubs in the Mediterranean area," Agronomy, vol. 9, no. 7, 2019, doi: 10.3390/agronomy9070381.

30. [30] O. A. M. Ali, "Wheat Responses and Tolerance to Drought Stress," in Wheat Production in Changing Environments, 2019.

31. [31] F. Gharbi, A. Guizani, L. Zribi, H. Ben Ahmed, and F. Mouillot, "Differential response to water deficit stress and shade of two wheat (Triticum durum desf.) cultivars: Growth, water relations, osmolyte accumulation and photosynthetic pigments," Pakistan J. Bot., vol. 51, no. 4, 2019, doi: 10.30848/PJB2019-4(4).

32. [32] J. Rane et al., "Relative tolerance of photosystem ii in spike, leaf, and stem of bread and durum wheat under desiccation," Photosynthetica, vol. 57, no. 4, 2019, doi: 10.32615/ps.2019.111.

33. [33] T. I. Allahverdiyev, J. M. Talai, and I. M. Huseynova, "Adaptive changes in physiological traits of wheat genotypes under water deficit conditions," Appl. Ecol. Environ. Res., vol. 16, no. 1, 2018, doi: 10.15666/aeer/1601_791806.

34. [34] I. Outoukarte, A. El Keroumi, A. Dihazi, and K. Naamani, "Use of Morpho-physiological 
Parameters and Biochemical Markers to Select Drought Tolerant Genotypes of Durum wheat," $J$. Plant Stress Physiol., vol. 5, pp. 01-07, 2019, doi: 10.25081/jpsp.2019.v5.3700.

35. [35] B. M. Olaolorun, H. A. Shimelis, I. Mathew, and M. D. Laing, "Optimising the dosage of ethyl methanesulphonate mutagenesis in selected wheat genotypes," South African J. Plant Soil, vol. 36, no. 5, 2019, doi: 10.1080/02571862.2019.1610808.

36. [36] R. Mangaiyarkarasi, M. Girija, and S. Gnanamurthy, "Mutagenic effectiveness and efficiency of gamma rays and ethyl methane sulphonate in Catharanthus roseus," Int.J.Curr.Microbiol.App.Sci, vol. 3, no. 5, pp. 881889, 2014, [Online]. Available: http://www.ijcmas.com.

37. [37] R. A. Satpute and R. V Fultambkar, "Effect of Mutagenesis on Germination, Survival and Pollen sterility in M 1 Generation of Soybean [ Glycine max ( L .) Merill ]," Int. J. Recent trends Sci. ad Technol., vol. 2, no. 3, pp. 30-32, 2012.

38. [38] A. Sourour, "A review: Morphological, physiological, biochemical and molecular plant responses to water deficit stress," Int. J. Eng. Sci., vol. 06, no. 01, 2017, doi: 10.9790/18130601010104.

39. [39] A. Guendouz, N. Semcheddine, L. Moumeni, and M. Hafsi, "The Effect of Supplementary Irrigation on Leaf Area, Speci c Leaf Weight, Grain Yield and Water Use Ef ciency in Durum Wheat (Triticum durum Desf.) Cultivars," Ekin J. Crop Breed. Genet., vol. 2, no. 1, 2016.

40. [40] M. À. Conesa, C. D. Muir, A. Molins, and J. Galmés, "Stomatal anatomy coordinates leaf size with Rubisco kinetics in the Balearic Limonium," AoB Plants, 2019, doi: 10.1093/aobpla/plz050.

41. [41] A. Blum, "Osmotic adjustment is a prime drought stress adaptive engine in support of plant production," Plant Cell and Environment, vol. 40, no. 1. 2017, doi: 10.1111/pce.12800.

42. [42] Amanullah et al., "Organic Matter Management in Cereals Based System: Symbiosis for Improving Crop Productivity and Soil Health," 2019.

43. [43] C. G. Chaib, G. Chaib, S. Merabta, M. Benlaribi, and N. Elmtili, "Markers of water stress in straw cereals (Triticum and Hordeum) at different phenological stages," Moroccan J. Biol. Number, vol. 1, no. 14, 2017, doi: 2351-8456.

44. [44] S. Keyvan, "The effects of drought stress on yield, relative water content, proline, soluble carbohydrates and chlorophyll of bread wheat cultivars," J. Anim. Plant Sci., vol. 8, no. 3, pp. 1051-1060, 2010, [Online]. Available: http://www.biosciences.elewa.org/JAPS;

45. [45] M. Karimpour, "Effect of Drought Stress on RWC and ChlorophyllContent on Wheat (Triticum Durum L.) Genotypes," World Essays J., vol. 7, no. 1, pp. 52-56, 2019.
46. [46] S. Arraouadi, M. Badri, W. Taamalli, T. Huguet, and M. E. Aouani, "Variability salt stress response analysis of Tunisian natural populations of Medicago truncatula (Fabaceae) using salt response index (SRI) ratio," African J. Biotechnol., vol. 10, no. 52, 2011, doi: 10.5897/ajb10.1784.

47. [47] D. Sándor et al., "Effects of Water Deficit and Salt Stress on some Photosynthesis Parameters in Wheat and Aegilops Comosa Lines," Acta Biol. Plant. Agriensis, vol. 7, pp. 55-67, 2019, doi: .1037//0033-2909.I26.1.78.

48. [48] Y. Nadia, "Photosynthèse, activité photochimique et tolérance au déficit hydrique chez le blé dur (Tritcum durum Desf)," Mentouri Constantine, Algérie, 2001. 